\title{
UM NOVO OLHAR SOBRE AS INTELIGÊNCIAS MÚLTIPLAS NA EDUCAÇÃO INFANTIL
}

\section{ARTIGO ORIGINAL}

COSTA, Tânia Gomes Ferreira da ${ }^{1}$

COSTA, Tânia Gomes Ferreira da. Um novo olhar sobre as Inteligências Múltiplas na Educação Infantil. Revista Científica Multidisciplinar Núcleo do Conhecimento. Ano 05, Ed. 05, Vol. 06, pp. 166-176. Maio de 2020. ISSN: 24480959, Link de acesso: https://www.nucleodoconhecimento.com.br/educacao/novoolhar

\section{RESUMO}

O presente trabalho investiga a possibilidade de implementação da proposta pedagógica das Inteligências Múltiplas. A fim de apresentá-la, a pesquisa propõe uma revisão da literatura acerca desse conceito. Parte-se da hipótese de que a Teoria das Inteligências Múltiplas reconhece a possibilidade de se trabalhar com recursos diversos, de forma interdependente, na prática pedagógica. Cada uma das formas de inteligência podem ser canalizadas para fins diversos e os símbolos criados por elas acarretam situações de aprendizagem diversas. Discutir sobre essas formas de inteligência é o objetivo desta proposta. Amparada por essa teoria, a pesquisa analisará a capacidade intelectual do educando na fase infantil, visando à estimulação da aprendizagem para o aperfeiçoamento individual e a integração social de cada um.

\footnotetext{
${ }^{1}$ Mestranda Em Educação- Universidad Grendal Estados Unidos da América Estado da Florida. Especialização em Gestão de Políticas Públicas em Gênero e RaçaUniversidade Federal da Bahia- UFBA. Especialização em Supervisão, Coordenação, Direção e Pedagogo Escolar- Faculdade São Mateus. Especialização em Orientação Educacional - Faculdades Integradas de Jacarepaguá - FIJ. Graduação em História - Faculdade de Ciências da Bahia - FACIBA. Graduação em Pedagogia Universidade do Estado da Bahia- UNEB.
} 
Propõe-se a compreender a educação no contexto das inteligências múltiplas que ocorre no ambiente escolar. Contextualiza as Inteligências Múltiplas como objeto de estudo e de pesquisa e privilegia a sua inserção como proposta pedagógica. Observase a implementação das Inteligências Múltiplas como um processo em construção, evidenciando a necessidade de mudanças na ação pedagógica do professor e no projeto político pedagógico da escola.

Palavras-chave: Educação Infantil, Inteligências múltiplas, escola.

\section{INTRODUÇÃO}

Este artigo tem como objetivo contextualizar a influência das inteligências múltiplas no desenvolvimento do ensino e aprendizagem na educação infantil. Compreende-se que tais inteligências, se bem compreendidas pelos educadores, podem ser trabalhadas de forma a promover o desenvolvimento das crianças no período pré-escolar. Ao lidar com crianças no ambiente escolar pode-se, de início, imaginar que haja um único tipo de existência. Porém, tal afirmativa é, hoje em dia, completamente errada, visto que, desde cedo, cada criança é capaz de despertar nas relações sociais diversas possibilidades de reação, dando ao aluno, ainda criança, uma complexidade capaz de ser mensurada (MENDONÇA, 2019).

As escolas, de modo geral, ignoram as demais competências que o ser humano é capaz de manifestar, limitando suas formas de aprender. Com base na prática pedagógica, observa-se que o processo educacional hoje está repleto de reprovações, evasão, desistência e desestímulo. São pontos negativos que não contribuem para a formação da cidadania (KLEMANN; NUNES, 2015). O aprender fica prejudicado principalmente pela falta de estímulo provocada por parte da escola. Esta instituição, que poderia valorizar a diversidade de competências do ser humano, tem contribuído para com a deficiência na aprendizagem por dar a atenção apenas a eixos como Linguagens e Matemática (MENDONÇA, 2019).

Somente aprendemos de forma duradoura quando somos transformados em centro de produção da aprendizagem e que essa se constrói a partir da interação entre as 
informações que chegam e são guardadas em nossos saberes. Os professores que lecionam nas séries iniciais do Ensino Fundamental têm uma parcela maior nesta trajetória do ensino-aprendizagem. A arte de ensinar mediada pelas escolas não tem favorecido a aquisição do conhecimento. É neste campo que há necessidade de se atuar com o objetivo de proporcionar condições para a criatividade que estimule o aprender. Devido a ênfase em uma inteligência em detrimento de outra, torna necessária a discussão sobre as suas dimensões para que se compreenda sua relevância.

\section{A TEORIA DAS INTELIGÊNCIAS MÚLTIPLAS: APONTAMENTOS}

A literatura aponta que em razão dos avanços da ciência cognitiva, ou seja, da ciência da mente, e, ainda, com a evolução da área da neurociência (que estuda a dimensão do cérebro), a inteligência humana passou por mudanças expressivas no que tange os aspectos epistemológicos e axiológicos que englobam a inteligência. Passou-se de uma tendência mais individual para uma coletiva (GÁSPARI; SCHWARTS, 2002; TRAVASSOS, 2001; MALAFAIA; RODRIGUES, 2011). Os estudos de Gardner foram decisivos para a substituição do paradigma unidimensional pelo multidimensional, e, assim, passou-se a compreender as múltiplas faculdades humanas como interdependentes. Nesse sentido, a Teoria das Inteligências Múltiplas tem como escopo explicar a cognição humana, bem como reconhece as diversas faces que a compõem e entende que elas estão interconectadas.

Para Gáspari e Schwarts (2002) isso explica o fato de que cada uma das formas de inteligência podem ser acionadas para fins diversos. Os símbolos construídos por essas inteligências podem migrar para outras, uma vez que há a interdependência entre essas dimensões. Inicialmente, havia sete inteligências mapeadas. Elas são a lógico-matemática, a linguística, a cinestésica-corporal, a musical, a espacial, a interpessoal e a intrapessoal (GÁSPARI; SCHWARTS, 2002; TRAVASSOS, 2001; MALAFAIA; RODRIGUES, 2011). Posteriormente, devido a popularização da teoria, e, sobretudo, em razão do apoio recebido pelas agências de fomento norteamericanas, outras inteligências foram adicionadas. Elas são a naturalista e a 
existencialista. De acordo com Gáspari e Schwarts (2002), a Teoria das Inteligências Múltiplas explica o porquê de uma pessoa parecer mais inteligente do que outra.

Assim sendo, do ponto de vista gardneriano, existem diferentes formas de se estimular e desenvolver as capacidades cognitivas (MOURA et al, 2016; MACHADO; CASTRO, 2019; SALES; ARAÚJO, 2018). Entretanto, há que se chamar atenção para o fato de que todos possuem essas capacidades, em condições potenciais. A primeira delas é a lógico-matemática: a partir do raciocínio lógico-dedutivo o sujeito é capaz de decodificar, analisar, sintetizar, compreender, avaliar e questionar os modelos socialmente impostos. Por meio da vivência se expressa frente a esses modelos, e, em alguns casos, os transforma. A segunda é a capacidade linguística. Há a associação do homem com a natureza e ela é fomentada pelos ambientes naturais. Estabelece-se uma comunicação figurada e o participante pode se expressar, por meio de uma linguagem própria, no meio social. A linguística permite que o homem viva a sua própria natureza.

A terceira capacidade é a corporal-cinestésica. Ela representa a habilidade para solucionar problemas inerentes à atividade humana. Precisa-se de movimentos do corpo inteiro e a partir dele o ser humano expressa, inclusive, os seus sentimentos, valores e concepções acerca do mundo que o circunda, de forma a superar as barreiras que os impede de viver de forma plena (GÁSPARI; SCHWARTS, 2002; TRAVASSOS, 2001; MALAFAIA; RODRIGUES, 2011). A quarta capacidade, por sua vez, é a musical. Parte-se do princípio de que a comunicação do homem no mundo real é estimulada a partir de formas diversas, como, por exemplo, pela percepção e utilização dos sons naturais como forma de expressão. As experiências com essa natureza coloca o homem em um constante estado de alerta, e, assim, é sensível aos sons, cheiros, sensações etc.

Ele representa, de modo simbólico, esses símbolos a partir do ritmo do seu próprio corpo, uma vez que ele se encontra em harmonia com o exterior. A quinta capacidade, por conseguinte, é a espacial. Trata-se de um modelo mental de espaços da realidade. A partir do conhecimento deles é possível a sua utilização e ocupação durante toda a vivência e, por razões diversas, um espaço pode ser substituído por outro mais 
adequado a um determinado momento da vida de quem o ocupa (MOURA et al, 2016; MACHADO; CASTRO, 2019; SALES; ARAÚJO, 2018). Esses espaços favorecem, ainda, a canalização de energias que poderiam estar reprimidas. A sexta habilidade é a capacidade interpessoal. É ela quem viabiliza o conhecimento e compreensão de uma outra pessoa. Mobiliza atitudes e valores inerentes ao relacionamento humano.

Eles são a cooperação, o respeito, a paciência, a solidariedade, a empatia, o reconhecimento da emoção alheia, a criticidade, a criatividade, o encorajamento pela busca por soluções sem que haja a imposição de ideias etc. São esses valores, articulados nas relações, que constroem o caráter do ser humano e o colocam como seres únicos e incomparáveis (GÁSPARI; SCHWARTS, 2002; TRAVASSOS, 2001; MALAFAIA; RODRIGUES, 2011). A sétima e última capacidade das originais da Teoria das Inteligências Múltiplas é a habilidade intrapessoal. Ela fomenta formas singulares de perceber o mundo e perceber-se nesse mundo. Elas são construídas na interação, e, de modo simbólico, são traduzidas na imagem que é construída por outrem sobre si. Valores como a confiança, a intencionalidade, o autocontrole e a curiosidade constroem essa imagem e, também, influenciam certas condutas.

Duas novas inteligências foram incorporadas às sete originais. A primeira é a naturalista. Compreende-se que vivências significativas possibilitam, ao homem, o reconhecimento de objetos do meio em que vive, bem como a distinção dos elementos vegetais, animais e minerais, e, ainda, o sujeito reconhece que possui um corpo e que é integrado e integrador na relação homem-natureza. A última inteligência é a existencialista. Ela fomenta uma reflexão sobre alguns aspectos inerentes à essência humana, como, por exemplo, a ideia de finitude, de transitoriedade, de condição de transcendência e outras questões inerentes à própria existência humana. Entende que o ser humano amplia as possibilidades de elevar-se, e, assim, de extrapolar os limites sociais quando precisa resistir. A partir dessa reflexão é possível pensar em como as inteligências humanas têm sido refletidas no âmbito pedagógico do ensino. 


\section{UM NOVO OLHAR SOBRE AS INTELIGÊNCIAS MÚLTIPLAS NA EDUCAÇÃO INFANTIL}

Tradicionalmente, a inteligência era considerada uma capacidade única, em geral, encontrada em graus variáveis em todos os indivíduos e necessária para um desempenho bem sucedido na escola. Relevando o sentido uniforme do passado Gardner (1995, p. 193) afirma:

O progresso na escola deve ser avaliado por testes formais frequentes. Estes testes devem ser administrados em condições uniformes, e os alunos, professores e pais devem receber resultados quantitativos que detalhem o progresso do aluno ou a falta desse progresso. Esses testes devem ser instrumentos com normas nacionais para possibilitar a máxima comparabilidade. As disciplinas mais importantes são as que se prestam mais prontamente a essa avaliação, tais como a matemática e a Ciência. Em outros assuntos, é atribuído o valor aos aspectos que podem ser avaliados eficientemente (a gramática, em vez da "voz" na escrita; os fatos, em vez da interpretação, na história,). As disciplinas que se mostram mais refratárias a testagem formal, tais como as artes são as menos valorizadas na escola uniforme.

Estimular a aprendizagem a partir das Inteligências Múltiplas já era uma preocupação constante nos estudos de Gardner, que reuniu suas pesquisas na publicação do seu primeiro livro "Estruturas da Mente". A Teoria das Inteligências Múltiplas, cujo fundamento é a pluralidade da mente, defende que as pessoas têm muitas inteligências e que a inteligência não se mede, e, ainda, frisa que essa poderá contribuir consideravelmente no processo ensino-aprendizagem, facilitando o desenvolvimento integral dos educandos (DORIA; SOARES, 2016). A ideia principal desses estudos é que o ser humano tem muitas inteligências. Nessa teoria a inteligência não se "mede". Na medida em que os diversos tipos de inteligência se 
manifestam de maneiras diferentes, tanto a avaliação quanto a estimulação precisam ocorrer de maneira adequada.

O que é estimulado no estágio de amamentação seria inadequado em estágios posteriores e vice-versa (GARDNER, 1995). O estudo da inteligência ocupa uma grande e diversificada área do conhecimento e por isto vem sendo ampliado, atualmente, por profissionais de inúmeras áreas, tais como: psicólogos, educadores, biólogos, engenheiros, médicos, bioquímicos, filósofos e sociólogos, entre outros. Cabe à nós, profissionais da educação, acompanhar e utilizar os resultados e os próprios processos destes estudos para atender cada vez mais e melhor a Educação e à pessoa, pois a inteligência é somente um dos muitos e complexos "capítulos" do ser humano (DORIA; SOARES, 2016). Para Miranda (1997, p. 131 apud ANTUNES, 2006, p. 195), "enquanto sujeito da história, a criança tem a possibilidade de recriar seu processo de socialização e através dele interferir na realidade social".

Ou seja, a criança pode ser sujeito da ação, apesar da constante repressão que a sociedade faz em oposição a isso. A escola ajuda na formação da personalidade da criança. A experiência do indivíduo com esse grupo, em grande parte, adquire informações particulares utilizadas num encontro educacional (GARDNER, 1994). As famílias diferem nos tipos de inteligências necessárias para o uso adequado, assim como os tipos de informações que elas apresentam com maior facilidade (KLEMANN; NUNES, 2015). Nota-se que crianças e adolescentes com boa vida social no lar e que encontram boas condições para o desenvolvimento do caráter não necessitam tanto de orientações por parte da escola e da sociedade. Deve-se reconhecer que é bem maior o número de indivíduos que necessitam ter na escola oportunidades que jamais tiveram em suas famílias (MENDONÇA, 2019).

Gardner (1995) destaca que que cada criança, conforme as trocas ocorrem no campo do aprendizado, aprendem novas formas de competências que as capacitam para o ajustamento social. Assim, cada competência desenvolvida pela criança deve ser valorizada, visto que os aspectos culturais de cada constituem pilares diferenciados que norteiam o desenvolvimento individualmente. Vale ressaltar que a importância dos esforços educacionais está em analisar o conceito historicamente construído na vida 
da criança e o contexto político e social de cada indivíduo, deixando explícito que a identidade construída para os diferentes tipos de criança de nossa realidade (urbanas e rurais, categorias socioeconômicas mais altas e mais baixas, meninos e meninas, etc) demanda diferentes investimentos para a construção de um desenvolvimento compatível com a dignidade humana (DORIA; SOARES, 2016).

Com relação as definições de inteligências múltiplas, destacam-se as que são apresentadas nos parágrafos seguintes, com suas caracterizações sucintas e correlações com o cotidiano da educação infantil. Concernente a questão de linguística, é uma condição tratada por diversas literaturas que relacionam o domínio desta inteligência com o saber expressar bem suas mensagens. Desenvolver bem habilidades, neste contexto, possibilita trabalhar, nas relações sociais, possibilidades de convencimento, estímulo e transmissão de informações, ideias e conceitos. $\mathrm{Na}$ infância, as histórias originais ao serem contadas podem refletir um pouco do exercício desse tipo de inteligência (DORIA; SOARES, 2016). Já a inteligência lógicomatemática possibilita que a criança desenvolva, com rapidez e exatidão, a projeção de conceitos, símbolos e fórmulas matemáticas.

Trata-se de uma habilidade que permite observar com profundidade categorias e padrões estimulados a partir da observação de objetos e símbolos, como, por exemplo, a capacidade despertada nas crianças de contar e fazer cálculos matemáticos (GARDNER, 1995). Um outro tipo de inteligência tão importante quanto os anteriores é a espacial, que consiste na capacidade de compreender o mundo via percepções visuais e espaciais. Trata-se de uma habilidade em que a criança pode desenvolver para, mentalmente, manipular formas e objetos, por exemplo. Profissionais como artistas plásticos, engenheiros e arquitetos desenvolvem continuamente esse tipo de inteligência. Na infância, um jogo simples e comum pode representar bem o desenvolvimento desta habilidade são os jogos de quebra-cabeça (GARDNER, 1995).

A inteligência denominada como físico-cinestésica consiste na habilidade de controlar o corpo para manipular objetos facilmente. É a habilidade desenvolvida por pessoas que adquirem uma coordenação plena de seus movimentos, como, por exemplo, os 
dançarinos, atletas e cirurgiões, dentre outros. As crianças que desenvolvem esta habilidade conseguem, com facilidade, mover-se delicada e ordenadamente ao escutarem sons musicais, por exemplo (DORIA; SOARES, 2016). A inteligência interpessoal é a habilidade do autoconhecimento, forma-se um conceito verídico sobre seu próprio comportamento, utilizando emoções e desejos com o objetivo de alcançar seus interesses pessoais de forma significativa e positiva. É o reconhecimento das habilidades que refletem no que é denominado como conjunto de inteligências próprias.

É o tipo de inteligência que denota na pessoa a ideia de ser bem resolvida e independente (KLEMANN; NUNES, 2015). A inteligência musical é outra competência relevante que se manifesta, habitualmente, a partir da capacidade que o indivíduo desenvolve para composições musicais e reprodução destas composições, principalmente em teatros musicais. É dotada da capacidade de percepção mais apurada de ritmos, sons e timbres, dentre outras particularidades. Trata-se da habilidade bem desenvolvida em profissionais como cantores e maestros. A criança que desenvolve esse tipo de habilidade consegue distinguir, desde cedo, tipos diferentes de sons e possuem o hábito de cantarem para si mesmas (DORIA; SOARES, 2016). A naturalista, ecológica ou biológica é considerada a oitava inteligência, uma das mais novas.

É a habilidade de identificar padrões da vida natural e vegetal. Essa habilidade consiste no desenvolvimento de linguagens naturais que consigam promover sensações bem definidas nas pessoas que se relacionam. Os indígenas, por exemplo, desenvolvem bem esse tipo de habilidade. Outras pessoas que lidam diretamente com a natureza, como botânicos e pessoas do campo também se distinguem com destaque no desenvolvimento desse tipo de habilidade (MENDONÇA, 2019). A nona inteligência descoberta é a pictográfica ou pictográficos, que consiste em mostrar a habilidade do desenho, que aparece como uma capacidade precoce desde a infância. Trata-se da capacidade de expressarem-se por meio de traços, desenhos e pinturas. Destacam-se neste tipo de inteligência os cartunistas, pintores, desenhistas e pessoas ligadas à arte (MENDONÇA, 2019). 
Todos estes estudos primam pela principal característica da inteligência que é a criatividade e a capacidade de resolver problemas, criando soluções que sejam socialmente úteis. São, então, importantes na busca pelo aperfeiçoamento das capacidades humanas criativas (GARDNER, 1995). A investigação acerca da estimulação da aprendizagem é impulsionada pelas diretrizes da teoria das Inteligências Múltiplas que são: não há uma inteligência maior que a outra. Todo mundo por si só tem condições de se desenvolver em todas as inteligências ou em algumas e que o desenvolvimento dessas inteligências é independente uma da outra Gardner (1995, p. 188) afirma:

A teoria das Inteligências Múltiplas prevê a valorização das diferenças e não a quantificação da inteligência. Os seres humanos são criaturas biológicas, mas são igualmente criaturas culturais. Mesmo antes do nascimento, o organismo imaturo está no útero de uma mulher que tem hábitos, estilos e práticas que refletem sua cultura e subcultura. E embora seja possível exagerar a influência dessas condições pré-natais, não há dúvida de que a vida do bebê após o nascimento está intrinsecamente relacionada às práticas e pressupostos de sua cultura.

Os educandos são diferentes. Isso é normal, pois eles são como a impressão digital: cada um possui o seu modo, afirma Mendonça (2019). Esta pesquisadora explica que com a ajuda das Inteligências Múltiplas, a criança desenvolve-se por inteiro, pois os canais de aprendizagem são tão múltiplos quanto as suas inteligências. Ainda segundo essa autora, a palavra de ordem nos estudos das inteligências Múltiplas é a inclusão. Todos têm potencialidades a desenvolver, nenhum ser humano é incapaz de aprender. No entanto, é preciso ser cauteloso quanto à obsessão por tentar estimular o cérebro o tempo inteiro, pois essa atitude é tão nociva quanto dar comida ao estômago em demasia, adverte Mendonça (2019).

A ajuda serena, na quantidade suportável, no tempo certo, é importantíssima. Por isso, essa mesma autora incentiva a aplicação de jogos como objetivo de estimular as habilidades do educando. Portanto, tudo que pode produzir uma excitação para o aluno poderá resultar na leitura da realidade como um todo, na busca de outros 
recursos e em fontes de pesquisa para uma descoberta melhor. A estimulação da aprendizagem proporciona, ao educando, o contato com diferentes pontos de vista sobre um determinado assunto e poderá confrontar ideias, não ficando apenas com uma opinião a respeito de seu tema (GARDNER, 1995).

Mendonça (2019) defende o jogo, em seu sentido integral, como o mais eficiente meio estimulador das inteligências, pois o espaço permite que a criança realize tudo o quanto deseja. O jogo não é uma tarefa imposta, não se liga a interesses materiais imediatos, mas absorve a criança, estabelece limites próprios de tempo, de espaço, cria ordem e equilibra ritmo com harmonia (KLEMANN; NUNES, 2015). É nesse processo de transformação que o educador pode proporcionar e estimular o rendimento da aprendizagem nas crianças e observar as descobertas das Inteligências Múltiplas por meio das atividades desenvolvidas na sala de aula.

\section{CONSIDERAÇÕES FINAIS}

Existem inúmeras vantagens numa avaliação realizada ao longo do tempo no ambiente da própria criança. Portanto, quatro maneiras poderão indicar como essa pesquisa da estimulação da aprendizagem a partir das inteligências múltiplas poderá beneficiar as crianças desde cedo: 1) engajamento do educando por meio de jogos significativos e contextualizados; 2) integração da avaliação e do programa educacional regular de forma mais objetiva; 3) ajustes para com a inteligência em operação e 4) sugestão de como a força de uma criança pode proporcionar o acesso à área em que ela pareça menos promissora. A possibilidade de identificar os talentos excepcionais das crianças numa idade bem inicial e de diferenciar os perfis de capacidades apresentadas pelos pré-escolares é relevante na identificação precoce das áreas de dificuldades e potencialidades.

Considerando o contexto apresentado, a pesquisa constatou que a melhor forma de se fomentar um melhor aproveitamento do potencial de cada criança se dá na descoberta do que lhe interessa ou lhe motiva, uma vez que esse fator é o que faz com que a criança se comporte ou pense de determinada maneira. A maior mudança necessária para a mudança de perspectiva é a abertura dos canais de manifestação 
e considerar o educando como proprietário do direito de optar por suas profundas formas de expressão. As crianças, desde o seu nascimento ou da tenra idade, já vêm com as inteligências múltiplas, porém cada ser humano desenvolve apenas algumas delas, o que nos dá um perfil particular de inteligência. A criança é a verdadeira potência do mundo e somente a partir dela é possível alimentar a esperança de construção de um mundo melhor.

Tanto na Educação Infantil como no Ensino Fundamental, os alunos aprendem a explorar o mundo e a descobrir coisas novas. Os conhecimentos precisam ser contextualizados pelos professores que, desenvolvendo a autonomia dos estudantes, procuram formar cidadãos capazes de atuar com responsabilidade na sociedade. $O$ estímulo à criatividade e ao espírito inventivo é característica de todo bom ensino. Toda situação de aprendizagem é uma transposição didática, e, por isso, é de fundamental importância um programa de estímulo ao desenvolvimento das diferentes inteligências, pois é sabido que a situação é crítica e está presente nos sistemas educacionais do país, e, portanto, essa responsabilidade não é só dos professores, alunos, corpo administrativo, mas de toda a comunidade escolar que deve se empenhar na construção do mesmo.

\section{REFERÊNCIAS}

ANTUNES, C. Inteligências Múltiplas e seus jogos: Introdução. Rio de Janeiro: Vozes, 2006.

BRASIL, Ministério da Educação e Desporto, Secretaria da Educação, Ensino Fundamental. Parâmetros Curriculares Nacionais, Introdução. Brasília: MEC, SEF, 1997.

DORIA, A. R. M.; SOARES, L. M. Inteligências múltiplas e aprendizagem significativa na educação infantil. In: I Seminário de Políticas Públicas Educacionais: desafios e perspectivas, 2016 . 
GARDNER, $\mathrm{H}$. Estruturas da Mente - $\mathbf{A}$ teoria das inteligências múltiplas. Porto Alegre: Artmed, 1995.

GÁSPARI, J. C. de.; SCHWARTS, G. M. Inteligências múltiplas e representações. Psicologia: Teoria e Pesquisa, v. 18, n. 3, p. 261-266, 2002.

KLEMANN, A. P.; NUNES, J. M. Educação Infantil na trilha das múltiplas inteligências: uma proposta de construção do conhecimento a partir das salas ambiente. Amazônia Revista de Educação em Ciências e Matemática, v. 12, n. 23, p. 44-57, dez. 2015.

MACHADO, L. V.; CASTRO, A. Uma experiência do Programa de Residência Pedagógica com a abordagem da Teoria das Inteligências Múltiplas. In: Seminário de Integração e Socialização de Pesquisas e Práxis Pedagógica em Matemática, 2019.

MALAFAIA, G.; RODRIGUES, A. S. de. L. O uso da teoria das inteligências múltiplas no ensino de biologia para alunos do ensino médio. SaBios-Revista de Saúde e Biologia, v. 6, n. 3, p. 8-17, 2011.

MENDONÇA, M. C. P. C. P. As inteligências múltiplas em contexto de educação pré-escolar: relatório final da prática de ensino supervisionado. 2019. 150 f. Tese (Mestrado em Educação Pré-Escolar) - Instituto Piaget, Campus Universitário de Almada, Almada, 2019.

MOURA, G. C. et al. A teoria das inteligências múltiplas e suas contribuições para a educação. Caderno de Graduação-Ciências Humanas e Sociais-UNIT-ALAGOAS, v. 3, n. 2, p. 153-168, 2016.

SALES, L. M. de. M.; ARAÚJO, A. V. de. A Teoria das Múltiplas Inteligências de Howard Gardner e o ensino do Direito. Novos Estudos Jurídicos, v. 23, n. 2, p. 682702, 2018.

TRAVASSOS, L. C. P. Inteligências múltiplas. Revista de biologia e ciências da terra, v. 1, n. 2, p. 0, 2001. 
Enviado: Março, 2020.

Aprovado: Maio, 2020. 